\title{
From the studio to the archive Art students and information literacy activities
}

$\mathbf{T}$ he university archives are so often the domain of "dusty historians" or serve as a source for nostalgia to encourage potential donors. As any archivist will tell you, however, these collections are cabinets of curiosity for the 21st century, containing ephemera and visual material that span the course of the institution. Engaging students with these collections can promote information and visual literacy objectives, as well as encourage retention by strengthening personal connections to the university itself. This article explores two assignments designed for studio art students using the archival resources at Oakland University in Rochester, Michigan, and describes their results.

\section{Background and planning}

Students in the photography program at Oakland University receive information literacy training from the Art librarian in nearly all of the classes for their major as part of a scaffolded program of instruction to ready them for their capstone thesis paper. When these sessions started, they took the form of traditional bibliographic instruction workshops, introducing photography students to library resources in the Arts, specifically the use of the library catalog and the research databases. It quickly became apparent, however, that although the students desperately needed the practice with these resources that such sessions afforded, their disassociation with hands-on artmaking was problematic. Despite faculty sharing their own research practices and lively dis- cussions about information-seeking and its impact on artmaking, the students resisted. This was further exacerbated by the lack of research papers or similar written projects in the studio art curriculum. Until they reach the thesis course, in fact, students simply do not do much in-major research and writing, so the aforementioned library sessions were often completely disconnected from their daily academic experiences.

In order to accommodate student needs and encourage more interest in the library and its resources, I have been working instead to develop active learning sessions that bridge the gap between research and artmaking. For example, some classes research a technique and artists who work in that technique before embarking upon a creative assignment that uses those skills. When the advanced new media art class comes in, students work in groups to research book alterations, assemblage, and found object art. After a presentation of their findings, they each choose a withdrawn library book to use as the basis of an art project that incorporates one of those techniques. As a follow-up to the instructional session, I attend a critique of their finished book art projects and exhibit the results in the library.

Working with the faculty to connect library sessions to studio art projects flexes

Katie Greer is Fine and Performing Arts librarian at Oakland University, email: greer@oakland.edu

๑ 2016 Katie Greer 
the librarian's creative muscles, as well. Often I am given a single term or idea (and once, memorably, a color), and I must find ways to help students use library resources to connect to it.

One photography professor became frustrated because his students struggled to interpret "duality" in art further than in very superficial, obvious ways when they were assigned a project around that theme. To address the problem and get the students using library resources, I developed a think-pairshare activity for students that they complete before they are given the duality assignment.

The students come to the library classroom and are divided into groups, with each group assigned an artist (in the past we've used Christian Boltanski, Edward Curtis, Leni Reifenstahl, and Cindy Sherman). Students then use part of the class time to research the artist using library resources. Then, in their groups, they present the artist and his or her work to the class, and everyone participates in a discussion about the notion of duality and how it is present in the artist's oeuvre.

The discussions serve as excellent opportunities for me to reinforce what the students are doing well when they seek out art and artist information, and also to point out other library resources that they may have not considered. The conversations that ensue also allow the professor to provide commentary and questioning to really stretch the students in their definition and understanding of duality in art and artmaking.

Student response has been overwhelmingly positive since these nontraditional, creative learning activities were incorporated into the library instruction sessions, and faculty report that the work they are receiving has more depth. Additionally, the newly appointed university archivist has been advocating for the use of the archival collections in student research projects. Its ongoing organization and the development of several online exhibitions featuring archival material have served to increase the archives' visibility and accessibility, and she wants to keep the momentum going.
After a visit to the archives, I concluded that incorporating the collections into select photography courses would fulfil several student learning and engagement outcomes, detailed below. Therefore, in fall 2014, an additional active learning component was developed-the use of the university archives as a teaching and learning collection for studio art students.

\section{Experience with primary sources}

Both ACRL and ARLIS/NA (Art Libraries Society of North America) recognize in their published information literacy competency standards that students need to be able to identify and use primary source documents. ${ }^{1}$ Primary resources in the arts include the works themselves, and experience in-person experience with art is probably the best way for students to engage with and understand art and art history. Outside of an official university museum or gallery, the archives can provide one of the best on-campus collections of art.

Engage with the visual culture of the university and its history

Research shows that students who are more engaged with their university, who genuinely feel a part of the campus and its activities, have higher completion rates. ${ }^{2}$ Given the current higher education focus on student retention and completion, having a selection of activities that align with larger strategic goals for student engagement and success can serve not only to promote student learning outcomes, but also to advance the library on campus.

The archival collections represent completely original material relevant to the university's history and mission, much of which is visual in nature: maps, architectural planning documents, photographic records of campus development and campus events, and other documentation of student and faculty presence on campus. Engaging with these materials can build deeper connections with places the students already know and experience. 
Fulfill information and visual literacy student learning outcomes

Although this may be an obvious connection, the use of the archives allows for a different experience with information and visual literacy objectives. If students are using images or other visual media for assignments, they gain experience with many of the visual literacy objectives as defined by ACRL, ${ }^{3}$ such as defining the need for an image or effectively accessing, analyzing, and using those images. In addition, the use of the archival material presents a unique opportunity to discuss and put into practice ethical behaviors, such as

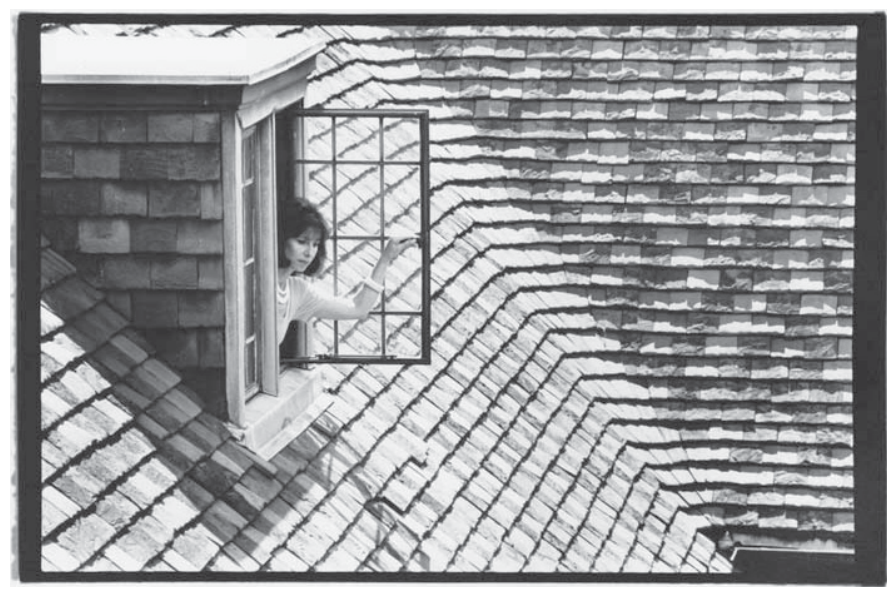

A woman at Meadow Brook Hall, looking out over the estate. Is she merely surveying the grounds or, as one student creatively suggested, overseeing a secret burial? (courtesy Oakland University Archives) so both assignments were constructed to provide writing experience without being overly onerous: the word-count requirements were relatively low and the assignments did not require outside knowledge or research. Both classes started with an introduction from the university archivist, who explained the purpose and scope of the collections and proper usage and handling policies. copyright and access policies related to the use of the collections.

\section{Activities}

During the fall semester of 2014, two photography classes came to the library archives and completed assignments using the collections. These classes already had student learning outcomes that were relevant to the archival collections, and so were a natural fit. SA350, Black and White Photography I, had an extensive unit on journalistic photography, so students could benefit from using the archival student newspaper collections; and SA 381, Advanced Photography, had a planned photo shoot at the historical home and museum on campus, Meadow Brook Hall, so the archival photographs relating to that building were relevant to their needs.

The photography professor wanted the students to have more experience writing, mow they felt the aesthetic decisions and how they felt the image fit into the story of the university (for example, many stories even then featured reports of new-building construction and woes about full parking lots, which spoke to the still-ongoing development of the young university and the ever-present frustrations with parking).

Inspired by an entry in the Embedded Librarian's Cookbook, ${ }^{4}$ the students in SA 381 were instructed to choose three images from a collection of photographs documenting events and happenings at the historic estate and construct a short narrative essay. The assignment encouraged the students to mention aesthetic qualities but to also feel free to be creative in the stories that they felt the pictures told as a whole.

Both activities fulfilled learning objectives related to analyzing and interpreting images. Additionally, because of the nature 
of the collection, the visits to the archives included a practical discussion of its ethical, legal, social, and economic issues, including why the archives exists, why the use restrictions exist, how these collections are typically used, and other concerns.

\section{Lessons learned}

In both classes it was fun to see the students connect with the material and discuss the similarities and differences between the campus now and in its past. The class examining the newspapers especially enjoyed not just the photography but also the advertisements, a bonus bit of visual culture that had not been anticipated when designing the assignment. One student requested to see material from the 1980s, noting that her father had been a student here during those years, so she was hoping to find images of him from his college days-a revelation that, again, spurred a great discussion among the students. Fashion choices, campus growth and accompanying growing pains, and the changing culture of university life were all hot topics for the day.

The students examining the Meadow Brook Hall event photographs similarly had a lively talk about what exactly was going on in the photographs (examples included an old car show, women sitting on Santa's lap, and a craft fair), the nature of the university fundraising system, and, again, how what they were seeing related to their own experience of the university and its culture.

Surprisingly, considering these were studio art students, the class that was asked to write a creative narrative resisted going beyond the strictures of the aesthetic critique. One particularly exemplary paper constructed an entertaining murder mystery, but otherwise most students stuck to the facts. All of the students reported that they enjoyed the visit to the archives, though, so for future sessions the guidelines will be tweaked to reflect their comfort level with less structured assignments.
What is perhaps most rewarding, however, is that the students gained appreciation for a collection that many of them had never realized existed, and through the use of these archives, the students may now feel comfortable approaching other collections.

Student comments about how fun it was to explore the old photographs, or how the light and tones of a particular image inspired one student to seek out older film photographic methods, reinforced the fact that hands-on experience with these archives can be rewarding and enjoyable while also contributing positively to student learning outcomes.

\section{Notes}

1. In Standard 1.2, outcomes e and f, ACRL notes that the information literate student: Differentiates between primary and secondary sources, recognizing how their use and importance vary with each discipline.

Realizes that information may need to be constructed with raw data from primary sources, www.ala.org/acrl/standards/informationliteracycompetency.

Similarly, in its enumeration of "advanced skills for all design students," ARLIS/NA notes that students should be able to "Effectively use advanced research sources to locate materials such as doctoral dissertations, unpublished research, artifacts, and primary documents," www.arlisna.org/images/researchreports /informationcomp.pdf, p. 32.

2. Patrick O'Keefe, "A sense of belonging: Improving student retention," College Student Journal 47, no. 4 (2013): 605.

3. ACRL Visual Literacy Competency Standards for Higher Education, www.ala.org/acrl /standards/visualliteracy

4. Erin Lawrimore, "Primary Source Stew: Helping Students Create a Historical Narrative Using Primary Sources in the University Archives," in The Embedded Librarian's Cookbook, ed. Kaijsa Calkins and Cassandra Kvenild (Chicago: ACRL, 2014): 90-91. n 